\title{
PHẪU THUẬT THAY VAN TIM CÓ TĂNG ÁP LỰC ĐỘNG MẠCH PHỔI NẶNG TẠI BỆNH VIỆN HỬU NGH!̣ VIỆT ĐỨC GIAI ĐOẠN 2014-2016
}

Đoàn Quốc Hưng*, Nguyễn Anh Huy*

TÓM TÁT: 70 trường hợp được phẫu thuật thay van tim có ALĐMP tâm thu $\geq 60 \mathrm{mmHg}$, trong đó có 54 trường hợp $(77,14 \%)$ được phẫu thuật thay VHL đơn thuần và 16 trường hợp (22,86\%) được phẫu thuật thay VHL phối hợp thay van ĐMC, có $46 \mathrm{BN}$ can thiệp trên VBL. Tuổi trung bình 48,12 $\pm 11,31$ (23-74 tuổi). Thời gian chạy tuần hoàn ngoài cơ thể trung bình 123,96 $\pm 57,27$ phút. Siêu âm đánh giá tình trạng van tim nhân tạo sau mổ: $100 \%$ trường hợp van hoạt động tốt; $1,43 \%$ hở cạnh van. Tỷ lệ tử vong sau mổ thấp $(1,43 \%)$, không có vỡ thất, không có chảy máu cần mổ lại. Áp lực động mạch phổi tâm thu giảm rõ sau mổ (từ 74,03 $\pm 13,71 \mathrm{mmHg}$ xuống 38,24 $\pm 10,94 \mathrm{mmHg}, \mathrm{p}=0,00)$. Phẫu thuật thay van tim trên $\mathrm{BN}$ có tăng áp lực ĐMP nặng vẫn là một lựa chọn khả thi, an toàn và hiệu quả.

Tù khóa: phẫu thuật thay van tim, tăng áp lực động mạch phổi nặng.

\section{HEART VALVE REPLACEMENT SURGERY}

AMONG PATIENTS WITH SEVERE PULMONARY ARTERIAL HYPERTENSION AT VIET DUC HOSPITAL IN 2014-2016.

\section{SUMMARY}

There were 70 patients undergoing valve replacement surgeries with pulmonary artery systolic pressure $\geq 60 \mathrm{mmHg}$, of which 54 cases $(77,14 \%)$ experienced mitral valve replacement surgery, 16 cases $(22,86 \%)$ underwent mitroaortic valve replacement surgery; and 46 cases had tricuspid valve repair. The mean age of patients were $48,12 \pm 11,31$ years old (range 23-74 years old). Time for extra corporeal circulation was long (123,96 $\pm 57,27$ minutes). Postoperative ultrasound showed that: $100 \%$ valves were well performed, and 1,43\% with perivalvular leak. The postoperative mortality was low $(1,43 \%)$; no case had ventricular rupture or bleeding that required reoperation. Systolic blood pressure of pulmonary artery was significantly reduced after the operation $(74,03 \pm 13,71 \mathrm{mmHg}$ to $38,24 \pm 10,94 \mathrm{mmHg}$, $\mathrm{p}=0.00$ ). Valve replacement surgery among patients with severe pulmonary arterial hypertension is still a good choice and safe solution.

Keywords: cardiac valve replacement, severe pulmonary arterial hypertension.

\section{I. ĐẶT VẤN ĐỀ}

Bệnh van tim, đặc biệt là bệnh van hai lá (VHL) và van động mạch chủ (ĐMC) là một trong những vấn đề lớn của bệnh tim mạch. Trong đó, những bệnh nhân có bệnh van tim kèm tăng áp lực động mạch phổi (tăng ALĐMP) là một trong những nhóm bệnh nhân cần được chú ý. Tăng ALĐMP là bệnh đặc trưng bởi sự tăng, tiến triển kháng trở mạch phổi gây nên khó thở, giảm hoặc mất khả năng vận động gắng sức, dẫn tới suy tim phải và tử vong sớm [1],[2]. Các tác giả nhận định tăng ALĐMP nặng làm tăng nguy cơ tử vong sau mổ gấp 2-3 lần so với không có hoặc tăng nhẹ áp lực động mạch phổi, kết quả theo dõi xa ở những bệnh nhân (BN) có tăng ALĐMP nặng cũng kém hơn so với nhóm tăng áp lực động mạch phổi nhẹ hoặc vừa [3],[4]. Do vậy trước đây việc chỉ định phẫu thuật ở nhóm bệnh này rất dè dặt, đa phần nghiêng về điều trị nội, không thay van.

Ngày nay, với sự phát triển về khoa học kỹ thuật, kinh tế, trình độ dân trí, nhiều $\mathrm{BN}$ bệnh van

\footnotetext{
* Khoa PT Tim mạch Lồng ngực BV Việt Đức-Truò̀ng ĐHY Hà Nội Nguò̀i chịu trách nhiệm khoa học: PGS.TS. Đoàn Quốc Hung Ngày nhận bài: 01/05/2018 - Ngày Cho Phép Đăng: 20/05/2018 Phản Biện Khoa học: GS.TS. Bùi Đức Phú PGS.TS. Đặng Ngọc Hùng
} 
tim có tăng ALĐMP nặng đã được tiếp cận với các cơ sở y tế để chẩn đoán và điều trị. Cùng với sự phát triển về khoa học y học, nhiều trung tâm phẫu thuật tim mạch và can thiệp tim mạch đã ra đời và phát triển, điều trị $\mathrm{BN}$ bệnh van tim ở các mức độ bệnh khác nhau, trong đó có bệnh van tim tăng ALĐMP nặng. Bệnh viện Hữu Nghị Việt Đức là một bệnh viện tuyến cuối hàng năm tiếp nhận chẩn đoán và điều trị nhiều $\mathrm{BN}$ bệnh van tim có tăng ALĐMP nặng, với số lượng $\mathrm{BN}$ ngày càng tăng. Vì vậy chúng tôi tiến hành nghiên cứu này nhằm mục tiêu nhận xét kết quả sớm điều trị phẫu thuật bệnh van tim có tăng áp lực động mạch phổi nặng tại bệnh viện Hữu Nghị Việt Đức giai đoạn 2014-2016.

\section{II. ĐỐI TƯợNG VÀ PHƯƠNG PHÁP NGHIÊN CÚU}

2.1. Đối tượng và địa điểm nghiên cứu: các $\mathrm{BN}$ được chẩn đoán bệnh van tim có tăng ALĐMP nặng, được phẫu thuật thay van tại khoa phẫu thuật Tim mạch-Lồng ngực Bệnh viện Hữu Nghị Việt Đức giai đoạn 2014-2016.

\section{Tiêu chuẩn lụa chọn bệnh nhân}

- Chẩn đoán xác định bệnh VHL và/ hoặc bệnh van ĐMC

- ALĐMP tâm thu trước mổ $\geq 60$ mmHg đo bằng siêu âm Doppler tim qua thành ngực.

- BN được phẫu thuật thay VHL, van ĐMC đơn thuần và/ hoặc phối hợp

- Có hoặc không phẫu thuật hoặc sửa van ba lá phối hợp.

- Hồ sơ bệnh án đáp ứng yêu cầu nghiên cứu.

\section{Tiêu chuẩn loại trù̀}

- Được thay VHL nhưng có kèm theo can thiệp trên ĐMC lên, động mạch vành.

- Có thương tổn tim bẩm sinh kèm theo (thông liên thất, thông liên nhĩ...)

- Thay lại van hoặc thay van sử dụng kỹ thuật ít xâm lấn (MICS)
- Các bệnh nhân có thông tin trong hồ so không đầy đủ.

2.2. Thiết kế nghiên cứu: Mô tả cắt ngang hồi cứu

2.3. Phương pháp chọn mẫu và cõ̃ mẫu: Chọn mẫu thuận tiện theo số đối tượng thu thập được trong thời gian nghiên cứu.

2.4. Biến số/chỉ số nghiên cứu: Các thông tin về nhân khẩu học, đặc điểm lâm sàng (tiền sử bệnh lý liên quan, tình trạng nhập viện, mức độ khó thở, phù phổi cấp, suy tim...), đặc điểm cận lâm sàng (điện tâm đồ, XQ tim phổi, siêu âm tim trước mổ...), đặc điểm phẫu thuật và kết quả sớm sau mổ được thu thập. Thu thập thông tin, số liệu từ hồ sơ bệnh án lấy từ phòng lưu trữ hồ sơ bệnh viện Việt Đức theo biểu mẫu thống nhất.

2.5. Xử lí và phân tích số liệu: Các số liệu được thu thập và xử lý bằng chương trình Epidata, STATA 13.0. Sử dụng các test: T-student, $X^{2}$ để kiểm định. Giá trị $\mathrm{p}<0,05$ được xem xét có ý nghĩa thống kê.

2.6. Đạo đức nghiên cứu: Nghiên cứu chỉ nhằm bảo vệ và nâng cao sức khỏe cho cộng đồng. Đối tượng nghiên cứu được cung cấp đầy đủ thông tin cần thiết,tự nguyện tham gia nghiên cứu. Các thông tin liên quan đến đối tượng được giữ bí mật, chỉ phục vụ cho mục đích nghiên cứu.

\section{KẾT QUẢ NGHIÊN CÚU}

Trong giai đoạn 2014-2016, có 70 trường hợp đủ tiêu chuẩn nghiên cứu, trong đó có 54 trường hợp $(77,14 \%)$ thay VHL đơn thuần và 16 trường hợp $(22,86 \%)$ được phẫu thuật thay VHL và van $\mathrm{ĐMC}$, có 46 trường hợp sửa van ba lá (VBL). Tuổi trung bình là 48,12 $\pm 11,31$ (tuổi), lớn nhất 74 tuổi, nhỏ nhất là 23 tuổi. $\mathrm{BN}$ ở độ tuổi lao động từ 30 đến 60 tuổi chiếm tỷ lệ cao nhất. BN là nữ giới chiếm đa số $66 \%$, tỷ lệ nữ/nam là 1,9 . 
Bảng 3.1. Các chỉ số siêu âm tim trước mổ $(n=70)$

\begin{tabular}{|l|c|c|c|}
\hline Các chỉ số & Nhỏ nhất & Lớn nhất & Trung bình \\
\hline Nhĩ trái $(\mathrm{mm})$ & 19 & 82 & $52,69 \pm 13,97$ \\
\hline Thất trái tâm trương $(\mathrm{mm})$ & 34 & 85 & $53,32 \pm 9,82$ \\
\hline Thất phải $(\mathrm{mm})$ & 16 & 44 & $26,21 \pm 6,11$ \\
\hline Phân xuất tống máu thất trái (EF\%) & 36 & 75 & $58,42 \pm 8,87$ \\
\hline ALĐMP tâm thu (mmHg) & 60 & 110 & $74,03 \pm 13,71$ \\
\hline
\end{tabular}

Bảng 3.2. Thương tổn ở van tim trên siêu âm $(n=70)$

\begin{tabular}{|l|c|c|c|c|}
\hline \multirow{2}{*}{ Thương tổn } & \multicolumn{2}{|c|}{ Van hai lá } & \multicolumn{2}{c|}{ Van ĐMC } \\
\cline { 2 - 5 } & $\mathbf{N}$ & $\mathbf{~ \%}$ & $\mathbf{n}$ & $\mathbf{\%}$ \\
\hline Dạng thấp & 58 & 82,9 & 30 & 81,1 \\
\hline Dạng Osler & 3 & 4,3 & 3 & 8,1 \\
\hline Dạng thoái hóa & 4 & 5,7 & 4 & 10,8 \\
\hline Dạng khác & 5 & 7,1 & 0 & 0,0 \\
\hline Tổng & 70 & 100,0 & 37 & 100,0 \\
\hline
\end{tabular}

Bảng 3.3. Thương tổn van ba lá trên siêu âm tim $(n=70)$

\begin{tabular}{|c|c|c|}
\hline Mức độ HoBL & $\mathbf{n}$ & Tỷ lệ (\%) \\
\hline $1 / 4$ & 5 & 7,14 \\
\hline $2 / 4$ & 29 & 41,43 \\
\hline $3 / 4$ & 33 & 47,14 \\
\hline $4 / 4$ & 3 & 4,29 \\
\hline Tống & 70 & 100 \\
\hline
\end{tabular}

$100 \% \mathrm{BN}$ đều tổn thương $\mathrm{HoBL}$, trong đó đa số mức độ hở vừa $(29 \mathrm{BN}=41,43 \%)$ và hở nặng (33 $\mathrm{BN}=47,14 \%$ ). $92,86 \% \mathrm{HoBL} \geq 2 / 4$.

Bảng 3.4. Loại van sử dụng (n=70)

\begin{tabular}{|c|c|c|c|c|}
\hline \multirow{2}{*}{ Đặc điểm van } & \multicolumn{2}{|c|}{ Can thiệp van hai lá } & \multicolumn{2}{c|}{ Can thiệp van ĐMC } \\
\cline { 2 - 5 } & $\mathbf{N}$ & $\mathbf{\%}$ & $\mathbf{n}$ & $\mathbf{\%}$ \\
\hline Cơ học & 42 & $60,0 \%$ & 12 & $75 \%$ \\
\hline Sinh học & 28 & $40,0 \%$ & 4 & $25 \%$ \\
\hline Tồng số & 70 & $100 \%$ & 16 & $100 \%$ \\
\hline
\end{tabular}

Bảng 3.5. Thời gian kẹp ĐMC và thời gian chạy máy tuần hoàn ngoài cơ thể (n=70)

\begin{tabular}{|l|c|c|c|}
\hline Thời gian & Nhỏ nhất & Lớn nhất & Trung bình \\
\hline Thời gian kẹp ĐMC (phút) & 32 & 133 & $100,99 \pm 44,38$ \\
\hline Thời gian chạy tuần hoàn ngoài cơ thể (phút) & 60 & 460 & $123,96 \pm 57,27$ \\
\hline
\end{tabular}


Bảng 3.6. Thuốc vận mạch sau mổ $(n=70)$

\begin{tabular}{|l|c|c|c|c|}
\hline \multirow{2}{*}{} & \multicolumn{2}{|c|}{ Vận mạch trong mổ } & \multicolumn{2}{c|}{ Vận mạch sau mổ } \\
\cline { 2 - 5 } & $\mathbf{n}$ & $\mathbf{\%}$ & $\mathbf{n}$ & $\mathbf{\%}$ \\
\hline Không thuốc & 1 & $1,9 \%$ & 4 & $5,7 \%$ \\
\hline Một thuốc & 29 & $54,7 \%$ & 43 & $61,5 \%$ \\
\hline Hai thuốc & 20 & $37,7 \%$ & 19 & $27,1 \%$ \\
\hline Phối hợp 3 thuốc trở nên & 3 & $5,7 \%$ & 4 & $5,7 \%$ \\
\hline
\end{tabular}

Trong mổ có $98,1 \%$ BN cần sử dụng thuốc vận mạch ngay sau thả kẹp ĐMC, trong đó 3 trường hợp $(5,7 \%)$ phối hợp ba thuốc. Sau mổ tỷ lệ BN dùng phối hợp hai hoặc ba thuốc vận mạch giảm xuống.

Bảng 3.7. Thời gian điều trị sau $m$ ổ $(n=70)$

\begin{tabular}{|l|c|c|c|}
\hline Thời gian & Nhỏ nhất & Lớn nhất & Trung bình \\
\hline Thời gian hậu phẫu (ngày) & 7 & 57 & $19,64 \pm 10,29$ \\
\hline Thời gian thở máy sau mồ (giờ) & 6 & 240 & $70,16 \pm 58,84$ \\
\hline Thời gian nằm hồi sức sau mồ (ngày) & 1 & 26 & $6,34 \pm 5,35$ \\
\hline Thời gian nằm viện sau mồ (ngày) & 7 & 57 & $19,64 \pm 10,29$ \\
\hline
\end{tabular}

Bảng 3.8. Biến chứng sớm sau mổ (n=70)

\begin{tabular}{|l|c|c|}
\hline Biến chứng & $\mathbf{n}$ & $\mathbf{\%}$ \\
\hline Tử vong & 1 & 1,4 \\
\hline Vỡ thất & 0 & 0,0 \\
\hline Chảy máu phải mố lại & 0 & 0,0 \\
\hline Tràn dịch màng ngoài tim & 2 & 2,9 \\
\hline TDMP, TKMP & 15 & 21,4 \\
\hline Phù phồi cấp & 0 & 0,0 \\
\hline Viêm phối & 0 & 0,0 \\
\hline Nhiễm trùng vết mổ & 0 & 0,0 \\
\hline Suy gan & 0 & 0,0 \\
\hline Suy thận & 1 & 1,4 \\
\hline Viêm nội tâm mạc & 0 & 0,0 \\
\hline Hở cạnh van nhân tạo & 1 & 1,4 \\
\hline Kẹt van nhân tạo & 0 & 0,0 \\
\hline Tắc mạch do dùng không đầy đủ thuốc chống đông & 0 & 0,0 \\
\hline Tắc mạch do dùng quá liều thuốc chống đông & 0 & 0,0 \\
\hline Suy tuần hoàn sau mố cần sử dụng ECMO & 0 & 0,0 \\
\hline Số bệnh nhân cần sử dụng bóng đối xung & 0 & 0,0 \\
\hline
\end{tabular}


Bảng 3.9. Các chỉ số siêu âm tim lúc ra viện $(\mathrm{n}=69)$ *

\begin{tabular}{|l|c|c|c|}
\hline $\begin{array}{l}\text { Chỉ số trên siêu âm tim } \\
\text { lúc ra viện }\end{array}$ & $\begin{array}{c}\text { Trước phẫu } \\
\text { thuật }\end{array}$ & Sau phẫu thuật & p \\
\hline Đường kính nhĩ trái $(\mathrm{mm})$ & $52,69 \pm 13,97$ & $49,57 \pm 8,00$ & 0,10 \\
\hline Đường kính thất trái tâm trương $(\mathrm{mm})$ & $53,32 \pm 9,82$ & $52,11 \pm 7,52$ & 0,41 \\
\hline Đường kính thất phải $(\mathrm{mm})$ & $26,21 \pm 6,11$ & $22,18 \pm 3,54$ & $\mathbf{0 , 0 0}$ \\
\hline Phân suất tống máu (EF\%) & $58,42 \pm 8,87$ & $58,18 \pm 8,71$ & 0,87 \\
\hline ALĐMP tâm thu (mmHg) & $74,03 \pm 13,71$ & $38,24 \pm 10,94$ & $\mathbf{0 , 0 0}$ \\
\hline
\end{tabular}

* Không tính 1 BN tư vong ngay sau mố

\section{BÀN LUẬN}

Nghiên cứu trên $70 \mathrm{BN}$ cho thấy, phương pháp siêu âm tim được sử dụng trong chẩn đoán trong nghiên cứu. Đây là phương pháp thăm dò cận lâm sàng quan trọng và hiệu quả trong chẩn đoán bệnh lý tim mạch nói chung. Siêu âm tim Doppler qua thành ngực cho phép xác định các thương tổn ở van tim, sự giãn các buồng tim, đo ALĐMP tâm thu cũng là một yếu tố quan trọng để tiên lượng bệnh. Bảng 3.1 cho kết quả đường

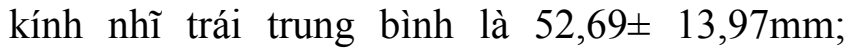
đường kính thất phải trung bình $26,21 \pm 6,11 \mathrm{~mm}$; đường kính thất trái tâm trương trung bình 53,32 $\pm 9,82$ mm, chức năng tim trung bình $(\mathrm{EF} \%)$ 58,4 $\pm 8,87$. Các thông số này cũng phù hợp với nghiên cứu của Đặng Hanh Sơn (2010) tại Viện tim Hà Nội [5] và Nguyễn Hồng Hạnh (2012) tại bệnh viện $\mathrm{E}$ [6]. Áp lực động mạch phổi tâm thu trong nghiên cứu của chúng tôi là 74,03 $\pm 13,71 \mathrm{mmHg}$, cao hơn nhiều so với các nghiên cứu của các tác giả trong nước như Đặng Hanh Sơn (2010) là $53,8 \pm 16,40$ mmHg, Nguyễn Hồng Hạnh (2012) là $52,6 \pm 18,0 \mathrm{mmHg}$ [5],[6].

Về thương tổn ở bộ máy VHL quan sát trên siêu âm, trong nghiên cứu của chúng tôi có $82,86 \% \mathrm{BN}$ có thương tổn van dạng thấp: lá van dày, co rút lá van và tổ chức dưới van (Bảng 3.2). Điều đó cho thấy đa phần căn nguyên gây bệnh VHL ở nước ta vẫn là hậu thấp. Thương tổn dạng thấp trên siêu âm đối với van ĐMC cũng cho kết quả tương tự $(81,08 \%)$.Kết quả này cũng tương đồng với các tác giả nghiên cứu trong nước khác [5], [11].

Trong bệnh lý van tim có tăng ALĐMP nặng, HoBL là thương tổn kèm theo hay gặp nhất. HoBL thường là hở cơ năng do giãn vòng van, hậu quả của giãn buồng thất phải khi thất phải co bóp để thắng được ALĐMP tăng cao. Áp lực động mạch phổi càng tăng cao thì thất phải càng co bóp mạnh hơn để thắng được sức cản, thất phải càng giãn và HoBL càng nặng nề. Hở van ba lá 2/4-3/4 cần can thiệp thu nhỏ vòng van trong mổ. Hở ba lá 4/4 nên dùng vòng van nhân tạo [7], [8]. Trong nghiên cứu của chúng tôi, $100 \% \mathrm{BN}$ đều có tổn thương HoBL, trong đó đa số mức độ hở vừa (29 $\mathrm{BN}=41,43 \%)$ và hở nặng (33 $\mathrm{BN}=47,14 \%$ ) (Bảng 3.3). So sánh với các tác giả khác, tỷ lệ HoBL trong nghiên cứu của chúng tôi có cao hơn, hậu quả của tăng ALĐMP lâu dài và nặng [7].

Kết quả nghiên cứu cho thấy, các $\mathrm{BN}$ được sử dụng tuần hoàn ngoài cơ thể thường quy, có hoặc không hạ thân nhiệt. Thời gian chạy máy tuần hoàn ngoài cơ thể nhỏ nhất là 60 phút, lâu nhất là 460 phút, trung bình là $123,96 \pm 57,27$ phút. Thời gian kẹp ĐMC nhỏ nhất là 32 phút, lớn nhất là 133 phút, trung bình là $100,99 \pm 44,38$ phút (Bảng 3.5). Thời gian kẹp ĐMC và chạy máy tuần hoàn ngoài cơ thể của chúng tôi có dài hơn một số nghiên cứu của các tác giả trong nước. Một phần vì thương tổn van nặng về, van 
dày, co rút và vôi hóa rất nhiều nên thao tác phải hết sức cẩn trọng. Một phần vì đa phần các $\mathrm{BN}$ trong nhóm nghiên cứu đều cần làm các thủ thuật can thiệp thêm như: lấy huyết khối nhĩ trái, khâu chân tiểu nhĩ trái.

Thời gian thở máy trung bình là $70,16 \pm 58,84$, thời gian nằm hồi sức trung bình $6,34 \pm 5,35$ ngày, thời gian nằm viện trung bình $19,64 \pm 10,29$ ngày. Có $7,14 \% \mathrm{BN}$ thở máy dưới 24 giờ, 24,29\% $\mathrm{BN}$ thở máy $24-48$ giờ và $68,57 \%$ $\mathrm{BN}$ thở máy $>48$ giờ. Thời gian nằm hồi sức phần lớn dưới 7 ngày (70\%). Thời gian thở máy của các $\mathrm{BN}$ trong nghiên cứu của chúng tôi dài hơn so với các nghiên cứu khác. Theo Nguyễn Hữu Ước (2005) có thời gian thở máy trung bình là 25,9 $\pm 20,5$ giờ, Nguyễn Xuân Thành (2010) là $24,3 \pm 36,24$ giờ [11]. Điều đó cho thấy những biến đổi về mô học ở động mạch phổi do hậu quả của tăng ALĐMP nặng kéo dài gây phức tạp, khó khăn cho điều trị sau mổ thay van.

Kết quả sớm sau mổ: có $1 \mathrm{BN}$ tử vong bệnh viện chiếm $1,43 \%$. Nguyên nhân tử vong do diê̂n biến suy tim cấp sau mổ, không đáp ứng với các thuốc vận mạch và trợ tim, rất tiếc $\mathrm{BN}$ không có điều kiện kinh tế để bệnh viện có thể thực hiện thêm các phương pháp hồi sức khác (ECMO, IABP). Tỷ lệ tử vong $1,43 \%$ khi tiến hành phẫu thuật trên nhóm BN nhiều nguy cơ như tăng ALĐMP nặng, theo chúng tôi là một kết quả rất đáng ghi nhận, điều đó chứng tỏ sự thuần thục trong kỹ thuật mổ, kỹ thuật chạy máy tuần hoàn ngoài cơ thể, đặc biệt là khả năng chăm sóc hồi sức sau mổ tại khoa phẫu thuật Tim mạch-Lồng ngực Bệnh viện Việt Đức. Najafi (1969) nghiên cứu thấy tỷ lệ tử vong là $16 \%$ ở nhóm có tăng ALĐMP vừa và $61 \%$ ở nhóm có tăng ALĐMP nặng [4]. Các nghiên cứu của các tác giả gần đây cho thấy tỷ lệ này có giảm xuống. Nirmal Kumar (2013) nghiên cứu thấy tỷ lệ tử vong ở nhóm có tăng ALĐMP nặng là 16,6\% [9]. Tỷ lệ tử vong trong nghiên cứu của chúng tôi cũng không cao hơn một số nghiên cứu thay van tim nói chung ở trong và ngoài nước.

Ngoại trừ 1 trường hợp tử vong bệnh viện, qua theo dõi 69 trường hợp còn lại trong thời gian hậu phẫu chúng tôi không gặp trường hợp nào bị vỡ thất, hay chảy máu phải mổ lại, không có trường hợp nào phải sử dụng $\mathrm{ECMO}$ hay bóng đối xung sau mổ. Tỷ lệ này thấp hơn so với tác giả Tạ Hoàng Tuấn (2016), nghiên cứu trên nhóm $\mathrm{BN}$ thay van ĐMC, 3 trường hợp chảy máu phải mổ lại $(1,95 \%), 9$ trường hợp phải dùng bóng đối xung $(5,84 \%)$ [10]. Có $1 \mathrm{BN}(1,43 \%)$ bị suy thận sau mổ, 15 trường hợp tràn máu trán khí khoang màng phổi tuy nhiên các trường hợp này đều được xử lý kịp thời không làm nặng thêm tình trạng của $\mathrm{BN}$. Trường hợp suy thận sau mổ cần phải siêu lọc nhưng cũng phục hồi nhanh và không làm thay đổi đáng kể kết quả điều trị.

Kết quả siêu âm tim kiểm tra sớm sau mổ cho thấy ALĐMP tâm thu giảm có ý nghĩa thống kê với $\mathrm{p}<0,05$ (Bảng 3.9). Điều này thực sự có ý nghĩa vì nó cho thấy hiệu quả ngay sau phẫu thuật thay van. Các chỉ số đường kính thất trái tâm trương $(\mathrm{Dd})$, phân suất tống máu thất trái $(\mathrm{EF} \%)$ thay đổi không có ý nghĩa thống kê so với trước mổ. Kết quả nghiên cứu này cũng phù hợp với kết quả của Đặng Hanh Sơn [5], Nguyễn Xuân Thành [11], Nguyễn Hồng Hạnh [6].Những biến đổi này là phù hợp với sinh lý bệnh sau mổ thay van. Kích thước buồng thất trái chưa thể giảm ngay, chức năng tim $(\mathrm{EF} \%)$ chưa thể cải thiện ngay sau mổ. Nguyễn Hồng Hạnh (2012) khi nghiên cứu về sự thay đổi huyết động sau mổ thay VHL cũng có nhận xét tương tự: đường kính nhĩ trái giảm ngay sau mổ, kích thước thất trái giảm có ý nghĩa ở nhóm có HoHL, còn nhóm HHL thì thất trái có xu hướng lớn hơn; chức năng tim $(\mathrm{EF} \%)$ thay đồi không có ý nghĩa ngay sau mổ cho tới thời điểm 6 tháng sau phẫu thuật [6]. 


\section{KẾT LUẬN}

Phẫu thuật thay van tim ở nhóm bệnh nhân bệnh van tim có tăng áp lực động mạch phổi nặng, dù còn tồn tại nhiều nguy cơ tử vong và biến chứng, nhưng đây vẫn là phương pháp chọn lựa để giúp cải thiện các triệu chứng và chức năng tim của bệnh nhân, góp phẫn làm giảm tỷ lệ tử vong do suy tim và tăng áp lực động mạch phổi cố định nếu không được phẫu thuật.

\section{TÀI LIỆ THAM KHẢO}

1. Marc Humbert, Joseph P. Lynch III (2009). Epidemiology of Pulmonary Arterial Hypertension. Lung Biology in Health and Disease, 236,10-19.

2. Kamal K and Mubarak (2009). A review of prostaglandin analogs in the management of patients with pulmonary arterial hypertension. Respiratory Medicine. 112, p. 1-13.

3. ACCF/AHA (2009). Expert Consensus Document on Pulmonary Hypertension. Journal of the American College of Cardiology. 53(17), 1573-1619.

4. Todd L. Kiefer, T.M. Bashore (2011). "Pulmonary Hypertension Related to LeftSided Cardiac Pathology". Pulmonary Medicine. 2011, 1-11.

5. Đặng Hanh Sơn (2010). Nghiên cứu đánh giá kết quả phẫu thuật thay van hai lá bằng van cơ học Sorin tại bệnh viện tim Hà Nội, Luận án tiến sĩ y học, Học viện Quân Y.

6. Nguyễn Hồng Hạnh (2012). Nghiên cứu biến đổi lâm sàng, huyết động trước và sau phẫu thuật thay van hai lá bằng van cơ học loại Saint Jude Master, Luận án tiến sĩ, Viện nghiên cứu khoa học y-dược lâm sàng 108.

7. Đoàn Quốc Hưng, Phạm Quốc Đạt, Nguyễn Hữu Ước (2013). Kết quả sau mổ van ba lá trong điều trị bệnh van tim mắc phải tại bệnh viện Hữu Nghị Việt Đức. Tạp chí tim mạch học Việt Nam. 64, 9-17.

8. Nguyễn Văn Phan (2014). Những yếu tố liên quan đến chỉ định can thiệp bệnh hở van ba lá đồng thời trong phẫu thuật thay van hai lá tại viện tim TP. HCM. Tạp chí phẫu thuật tim mạch và lồng ngực Việt Nam. 6, 3-8.

9. T. K. Kaul (1976). Mitral valve replacement in the presence of severe pulmonary hypertension". Thorax. 31, 332-336.

10. Tạ Hoàng Tuấn, Đặng Hanh Sơn, Đoàn Quốc Hưng (2016). Đánh giá kết quả thay van ĐMC cơ học Sorin Bicarbon tại BV Tim Hà Nội giai đoạn 2009-2014. Tạp chí tim mạch học Việt Nam, 74, 24-31.

Nguyễn Xuân Thành (2010). Nghiên cứu đặc điểm lâm sàng, cận lâm sàng và kết quả phẫu thuật thay van hai lá có huyết khối nhĩ trái tại bệnh viện Việt Đức, Luận văn thạc sĩ, Đại học Y Hà Nội. 